\title{
Studies on the Metabolism of the Protozoa
}

\section{COMPARATIVE METABOLISM OF BLOOD-STREAM AND CULTURE FORMS OF TRYPANOSOMA RHODESIENSE*}

\author{
BY J. F. RYLEY \\ Imperial Chemical Industries Ltd., Pharmaceuticals Division, Alderley Park, Macclesfield, Cheshire
}

(Received 17 April 1962)

Trypanosoma rhodesiense in Nature has a lifecycle involving marked changes in habitat and displaying corresponding changes in morphology. Thus in the blood-stream of the mammalian host, under conditions of elevated temperature and presumably rich oxygen supply, a variety of forms occur (polymorphism) ranging from long slender flagellates through intermediate types to short stumpy trypanosomes; in each case the kinetoplast from which the flagellum originates is situated posterior to the nucleus. The cytoplasm of the short stumpy form contains a number of 'volutin granules' which are seen as refractile bodies by phase-contrast microscopy; the long slender forms are free from these RNA-containing inclusions (Ormerod, 1958, 1961). When the tsetse fly takes a meal of infected blood, the trypanosomes are transferred to an environment at a lower temperature with presumably a less plentiful oxygen supply. Here in the gut the trypanosomes multiply, all becoming long and slender in form, with the kinetoplast still posterior to the nucleus. During this period of multiplication the trypanosomes migrate considerably through the alimentary tract, and eventually invade the proboscis and salivary glands. Here the positions of nucleus and kinetoplast are gradually reversed; the resulting crithidia, which display a different type of body movement, become attached to the walls of the gland, multiply and, finally, after a further reversal of kinetoplast and nucleus, give rise to metacyclic trypanosomes, morphologically similar to but smaller than the blood forms. These are the only forms in the fly capable of initiating infection in the mammalian host. It is of interest to correlate changes in habitat and morphology with changes in metabolism during the life-cycle, and to determine which of the factors is cause and which effect. The present paper reports some biochemical differences and similarities found between the blood forms of a rat-adapted strain of $T$. rhodesiense and the forms grown in 'cold' culture. Some of these findings have been suggested by studies carried out with the corresponding forms of Trypanosoma gambiense

* Part 8: Archibald, Hirst, Manners \& Ryley (1960).
(Brand, Weinbach \& Tobie, 1955; Fulton \& Spooner, 1959), and some have been briefly reported elsewhere (Ryley, $1961 a, b$ ).

\section{MATERIALS AND METHODS}

Organisms. The blood-stream form of $T$. rhodesiense used in the present work has been maintained by syringe passage in rats or mice for many years, and is the strain used by Ryley (1956). Under the conditions of passage used, it produced a fulminating infection in rats, causing the death of the animal 3 or 4 days after inoculation. The trypanosome strain is monomorphic, all the organisms being of the long slender type: the strain could not be established in culture, and presumably was not infective for tsetse flies or man (Ashcroft, 1960). The Wellcome C.T. strain of $T$. rhodesiense was obtained in culture from Dr T. von Brand in August 1955; the strain had been isolated from man in October 1934 and passaged by tsetsefly transmission in animals until December 1946; it was isolated in culture from infected rats in March 1947. The flagellates were all of the long slender trypanosome type, corresponding morphologically to the form found in the mid-gut of the tsetse fly (Trager, 1959). Although the cultures were not infective for rats, a preliminary experiment suggests they may be able to infect and develop in tsetse flies. Gordon \& Miller (1961) described an experiment in which trypanosomes that had been maintained in culture over 32 passages (a period of 18 months), when mixed with heparin-treated human blood and fed through a guinea-pig-skin membrane to tsetse flies, produced an infection in the fly which developed to the metacyclic stage by the 27th day, and was able to give rise to a polymorphic infection in guinea pigs. Mr Miller attempted to repeat the work with the present strain of $T$. rhodesiense in December 1961, since this strain had been maintained in culture for 14 years in contrast with his strain, which had been in culture for only 18 months. About 50 Glossina morsitans were fed on citrated human blood containing culture trypanosomes. Dissection of the tsetse flies at various intervals showed that about $30 \%$ of the individuals had persistent gut infections (i.e. at more than 2 days after the infective feed) and that two flies had established fore-gut infections at 14 days.

When examined by phase-contrast microscopy, the blood-stream trypanosomes showed a clear cytoplasm; by contrast, in the cytoplasm of the culture forms a number of refractile volutin granules were observed, arranged in two groups on either side of the centrally situated nucleus.

Trypanosome preparations. Culture trypanosomes were 
grown at $24^{\circ}$ in the medium of Tobie, Brand \& Mehlman (1950), except that citrated bovine blood was used for large-scale culture. Usually 36 conical flasks of $250 \mathrm{ml}$. capacity, each containing $25 \mathrm{ml}$. of the blood-agar base (Oxoid Lab-lemco, 2.25 g.; Oxoid peptone, 3.75 g.; NaCl, 6 g.; agar, 15 g.; water, $750 \mathrm{ml}$; $\mathrm{pH} 7 \cdot 2-7 \cdot 4$; autoclaved at $15 \mathrm{lb}$./in. ${ }^{2}$ for $20 \mathrm{~min}$., cooled to $56^{\circ}$ and $250 \mathrm{ml}$. of inactivated citrated bovine blood added) and $15 \mathrm{ml}$. of overlay, provided sufficient material for one experiment; cultures were harvested after 6 days, which corresponds to the stationary phase of the growth curve. Blood-stream trypanosomes were isolated from the blood of infected rats by differential centrifuging as described by Ryley (1956). With the very heavy infections of $T$. rhodesiense obtained just before death, the preparation of trypanosome suspensions in a fairly pure state was not difficult. Sometimes a few contaminating erythrocytes were present, and also, with some batches of culture trypanosomes, red cells derived from the blood-agar base were present. These were destroyed by adding to a thick (approx. 10\%, v/v) suspension of trypanosomes an excess of the corresponding antiserum prepared in rabbits, and, after standing for 3 min. at $30^{\circ}$, a small amount of guinea-pig serum; this caused lysis of the few red cells present. After being washed, such preparations were suitable for use. Trypanosome preparations were washed and suspended in the Ringerphosphate or Ringer-bicarbonate solutions detailed by Ryley (1955), which contained where necessary $1.3 \mathrm{mg}$. of glucose or glycerol $/ \mathrm{ml}$. Cell-free homogenates were prepared by suspending trypanosomes in water (4-6 vol.) and freezing the suspension at $-70^{\circ}$ with subsequent thawing in a water bath at $30^{\circ}$, the freezing and thawing cycle being carried out twice (see Grant, Sargent \& Ryley, 1961). Where necessary, homogenates were dialysed, with stirring, for $1 \frac{1}{2}$ hr. at $2^{\circ}$ against water.

Metabolic experiments. Spectroscopic observations, manometric experiments and the subsequent estimation of metabolites were carried out as described by Ryley (1955); manometer flasks were shaken through an arc of $2.7 \mathrm{~cm}$. at 148 complete oscillations/min. Volatile acid, as estimated by the distillation of a tungstic acid filtrate in the presence of mercuric oxide and titration as described by Buchanan, Sakami, Gurin \& Wilson (1947), was considered to be acetic acid; the method was standardized by the distillation of known amounts of sodium acetate.

Spectrophotometric experiments. These were carried out in the Unicam SP. 500 spectrophotometer with $1 \mathrm{~cm}$. silica cells and nicotinamide-adenine nucleotides obtained from C. F. Boehringer und Soehne G.m.b.H., Mannheim, Germany.

\section{RESULTS}

\section{Substrate utilization}

The motility and respiration of both culture and blood-stream forms of $T$. rhodesiense depends on a supply of extracellular substrate. The detailed metabolism of three substrates, glucose, glycerol and succinate, has been investigated with whole cells and cell extracts.

Culture forms. The greatest rate of oxygen consumption was obtained with glycerol, glucose, fructose and mannose supporting respiration at about two-thirds this rate; other mono- and di- saccharides, including trehalose, were without effect (Table 1). Of a number of tricarboxylic acidcycle intermediates tested, $\alpha$-oxoglutarate and succinate, and to a lesser extent malate, fumarate and citrate, stimulated oxygen uptake, but these effects were only marked under acid conditions. Of the other substances examined, glutamate and glutamine supported a low rate of respiration. In the presence of glucose, respiration continued at an almost linear rate for at least $2 \mathrm{hr}$.

Blood forms. Blood forms when isolated in washed suspension were much more sensitive to handling than were the culture flagellates, and did not long retain an intact cellular structure in the absence of utilizable substrate. Even when the latter was present, respiration gradually declined and ceased after $\frac{1}{2}-1 \frac{1}{2} \mathrm{hr}$. shaking in a manometer flask. All the substances detailed in Table 1 were tested with blood forms, but, owing to the instability of the respiratory rate, only a qualitative assessment of the effect has been made. Glycerol, glucose, fructose and mannose were all equivalent in supporting a high initial rate of respiration; in the presence of glycerol, trypanosomes survived for about twice as long as in the presence of the other sugars. None of the other substances listed in Table 1 increased the respiration. At $\mathrm{pH} 5 \cdot 6$, no respiration took place in the presence of either glucose or the dicarboxylic acids.

\section{Glucose and glycerol metabolism}

Substrate utilization. An investigation was made of the utilization of glucose and glycerol under

Table 1. Effect of extracellular substrate on the respiration of culture forms of Trypanosoma rhodesiense

Each manometer flask contained trypanosomes (1-2 mg. of $\mathrm{N}$ ) in $1.2 \mathrm{ml}$. of Ringer-phosphate; $0.3 \mathrm{ml}$. of $0.1 \mathrm{M}$ substrate was tipped from the side bulb, and the oxygen uptake was followed for $1 \mathrm{hr}$. at $30^{\circ}$. The values represent oxygen uptakes calculated on a basis of glucose $=100$, and are the averages of two to four separate determinations. No increase in respiration was detected with galactose, maltose, lactose, sucrose, trehalose, inositol, arabinose, formate, acetate, pyruvate, lactate, alanine, aspartate, asparagine and ethanol.

\section{Substrate}

None

Glucose

Fructose

Mannose

Glycerol

$\alpha$-Oxoglutarate

Succinate

Malate

Fumarate

Citrate

Glutamate

Glutamine

$\overbrace{\mathrm{pH} 7 \cdot 3}^{2} \begin{array}{cc}\text { RH 5·6 } \\ 4 & 6 \\ 100 & 100 \\ 110 & - \\ 91 & - \\ 147 & - \\ 32 & 230 \\ 27 & 175 \\ 7 & 62 \\ 5 & 23 \\ 5 & 16 \\ 18 & - \\ 23 & -\end{array}$


various conditions: both phosphate and bicarbonate buffers have been used under aerobic and anaerobic conditions (Table 2). Carbon dioxide was essential for substrate utilization by culture forms under anaerobic conditions, and was stimulatory under aerobic conditions. With blood forms, carbon dioxide, although it plays no part in glucose metabolism, stimulated the anaerobic utilization of glucose, but had no effect on the aerobic utilization of glucose or glycerol; glycerol was not utilized under anaerobic conditions and it is a metabolic product of anaerobic glucose metabolism. Table 3 indicates the relative amounts of substrate used in the presence of carbon dioxide under both aerobic and anaerobic conditions when glucose or glycerol was supplied separately or together. Culture forms under both aerobic and anaerobic conditions used glycerol in absolute preference to glucose when both substrates were available. With the blood forms, however, both substrates were utilized in mixtures under aerobic conditions; anaerobically glycerol, although not utilized itself, almost completely suppressed glucose utilization.
Metabolic products. The products of glucose and glycerol metabolism in the presence of a carbon dioxide-bicarbonate buffer under both aerobic and anaerobic conditions have been investigated; in Table 4 the results of anaerobic experiments of this type are summarized. In the culture forms, with both glucose and glycerol, there was a net assimilation of carbon dioxide; the major metabolic product was succinic acid, with acetic acid also being produced, particularly from glucose. With blood forms, glycerol was not metabolized anaerobically; glucose gave rise to pyruvic acid and glycerol (Ryley, 1956).

Aerobically, the course of metabolism is more complicated. With blood forms, glycerol was converted largely into pyruvic acid, with a very low R.Q. (Table 5). Pyruvic acid was the major end product of aerobic glucose metabolism (Ryley, 1956); the small amount of glycerol accumulating would have been utilized with longer incubation or would possibly not have accumulated had there been more vigorous aeration. Aerobically glucose and glycerol were oxidized by culture forms mainly

Table 2. Effect of gas phase on substrate utilization by culture and blood forms of Trypanosoma rhodesiense

Each manometer flask contained trypanosomes (culture form, 1.63 mg. of $\mathrm{N}$; blood form, 1.04 mg. of $\mathrm{N}$ ) with $2 \mathrm{mg}$. of glucose or glycerol in $1.5 \mathrm{ml}$. of Ringer-phosphate or Ringer-bicarbonate; the gas phase was as indicated. Incubation was carried out at $30^{\circ}$ (culture form, $40 \mathrm{~min}$.; blood form, $20 \mathrm{~min}$.) and the reaction stopped by tipping $0.3 \mathrm{ml}$. of $2 \mathrm{~N}-\mathrm{H}_{2} \mathrm{SO}_{4}$ from the side bulb. Glucose or glycerol was estimated in $\mathrm{Ba}(\mathrm{OH})_{2}-\mathrm{ZnSO}_{4}$ filtrates of initial and final samples.

\begin{tabular}{|c|c|c|c|c|c|}
\hline \multirow[t]{2}{*}{$x-10$} & & \multicolumn{4}{|c|}{ Gas phase } \\
\hline & & $\mathrm{N}_{2}$ & $\underset{(5: 95)}{\mathrm{CO}_{2}+\mathrm{N}_{2}}$ & Air & $\begin{array}{c}\mathrm{CO}_{2}+\mathrm{air} \\
\quad(5: 95)\end{array}$ \\
\hline $\begin{array}{l}\text { Form of } \\
\text { organism }\end{array}$ & Substrate & \multicolumn{4}{|c|}{ Substrate utilized ( $\mu$ moles) } \\
\hline Culture & $\begin{array}{l}\text { Glucose } \\
\text { Glycerol }\end{array}$ & $\begin{array}{l}0.00 \\
0.00\end{array}$ & $\begin{array}{l}7 \cdot 25 \\
5 \cdot 95\end{array}$ & $\begin{array}{l}4 \cdot 85 \\
9 \cdot 03\end{array}$ & $\begin{array}{r}6 \cdot 39 \\
15 \cdot 51\end{array}$ \\
\hline Blood & $\begin{array}{l}\text { Glucose } \\
\text { Glycerol }\end{array}$ & $\begin{array}{l}2.17 \\
0.00\end{array}$ & $\begin{array}{l}7 \cdot 06 \\
0 \cdot 00\end{array}$ & $\begin{array}{r}9 \cdot 93 \\
11 \cdot 41\end{array}$ & $\begin{array}{r}9.91 \\
11.56\end{array}$ \\
\hline
\end{tabular}

Table 3. Utilization of glucose and glycerol in mixtures by culture and blood forms of Trypanosoma rhodesiense

Each manometer flask contained trypanosomes with $2 \mathrm{mg}$. of glucose or glycerol or both in 1.5 ml. of Ringerbicarbonate; the gas phase was $\mathrm{CO}_{2}+$ air $(5: 95)$ or $\mathrm{CO}_{2}+\mathrm{N}_{2}(5: 95)$; the temperature was $30^{\circ}$.

\begin{tabular}{|c|c|c|c|c|c|c|c|}
\hline \multirow[b]{2}{*}{$\begin{array}{l}\text { Form of } \\
\text { organism }\end{array}$} & \multirow[b]{2}{*}{$\begin{array}{c}\text { Gas } \\
\text { phase }\end{array}$} & \multirow[b]{2}{*}{ Substrate } & \multicolumn{3}{|c|}{ Substrate utilized ( $\mu$ moles) } & \multirow[b]{2}{*}{$\begin{array}{c}\text { Amount of } \\
\text { organism } \\
\text { (mg. of } N \text { ) }\end{array}$} & \multirow[b]{2}{*}{$\begin{array}{c}\text { Incubation } \\
\text { time } \\
\text { (min.) }\end{array}$} \\
\hline & & & Glucose & Glycerol & $\begin{array}{c}\text { Glucose } \\
+ \\
\text { glycerol }\end{array}$ & & \\
\hline Culture & $\begin{array}{l}\mathrm{CO}_{2}+\mathrm{air} \\
\mathrm{CO}_{2}+\mathrm{N}_{2}\end{array}$ & $\begin{array}{l}\text { Glucose } \\
\text { Glycerol } \\
\text { Glucose } \\
\text { Glycerol }\end{array}$ & $\begin{array}{c}5 \cdot 30 \\
7 \cdot 42 \\
-\end{array}$ & $\begin{array}{c}\overline{12 \cdot 10} \\
\overline{4 \cdot 55}\end{array}$ & $\left.\begin{array}{r}0.00 \\
11.07 \\
0.70 \\
5.96\end{array}\right\}$ & $1 \cdot 77$ & 26 \\
\hline Blood & $\begin{array}{l}\mathrm{CO}_{2}+\mathrm{air} \\
\mathrm{CO}_{2}+\mathrm{N}_{2}\end{array}$ & $\begin{array}{l}\text { Glucose } \\
\text { Glycerol } \\
\text { Glucose } \\
\text { Glycerol }\end{array}$ & $\begin{array}{c}10 \cdot 20 \\
\frac{6 \cdot 94}{-}\end{array}$ & $\begin{array}{c}\overline{12 \cdot 88} \\
\overline{0.00}\end{array}$ & 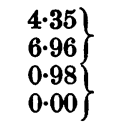 & $\begin{array}{l}1.04 \\
1.91\end{array}$ & 25 \\
\hline
\end{tabular}


to carbon dioxide, with a small amount of acid which included acetic acid and succinic acid (Table 5); in contrast with the blood forms, the R.Q. was high; no lactic acid or pyruvic acid was found. During the initial stages of incubation substrate was utilized rapidly and oxidation was incomplete; as incubation proceeded and the substrate became exhausted, oxygen uptake continued, with in general an increase in R.Q. and in acetic acid, and a decrease in total acid, including succinic acid and presumably other unidentified metabolites. Table 5 indicates a net utilization of succinic acid after incubation for $150 \mathrm{~min}$. in the presence of glucose; owing to the design of the Dickens \& Simer manometer flasks it was not possible to add the substrate at the beginning of the experiment (the single side bulb contained acid to stop metabolism and to destroy bicarbonate when required), and the trypanosomes were therefore suspended in Ringer-bicarbonate already containing substrate; analysis indicated that appreciable quantities of succinate accumulated during the pre-experimental period. No account has been taken of any endogenous metabolism which may have contributed to oxygen uptake, especially after the exhaustion of added glucose or glycerol; Table 1 suggests, however, that this contribution would be small.

Table 4. Products of anaerobic metabolism of glucose and glycerol by culture and blood forms of Trypanosoma rhodesiense

Culture trypanosomes were incubated with glucose or glycerol (2 mg. per flask) in a Ringer-bicarbonate medium (1.5 ml. per flask) at $30^{\circ}$ with a gas phase of $\mathrm{CO}_{2}+\mathrm{N}_{2}$ (5:95). Fermentation was stopped by tipping in acid from the side bulb. Initial and final values were each based on the combined contents of four manometer flasks. The values give the total amount of substrate'used, and the amounts of metabolites recovered, expressed in terms of moles of metabolite/mole of substrate used. Values for blood forms $\left(37^{\circ}\right)$ taken from Ryley (1956) are included for comparison.

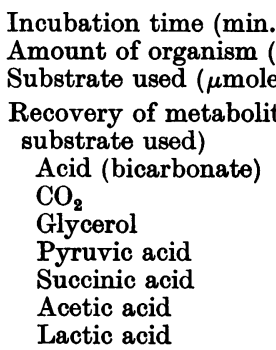

$\begin{array}{ccc}\overbrace{\text { With glucose }} \text { Culture form } & \text { With glycerol } & \begin{array}{c}\text { Blood form } \\ \text { with glucose }\end{array} \\ 50 & 40 & 60 \\ 1.84 & 2 \cdot 33 & \\ 30.18 & 45.30 & 24.40 \\ & & \\ +2.76 & +1.69 & +1.19 \\ -0.70 & -0.89 & +0.05 \\ 0.00 & -1.00 & +1.03 \\ +0.01 & 0.00 & +0.83 \\ +1.13 & +0.95 & +0.04 \\ +0.75 & +0.11 & 0.00 \\ 0.00 & 0.00 & +0.05\end{array}$

Table 5. Aerobic metabolism of glucose and glycerol by culture and blood forms of Trypanosoma rhodesiense

Each Dickens \& Šimer manometer flask contained trypanosomes in $2 \mathrm{ml}$. of Ringer-bicarbonate-glucose or Ringer-bicarbonate-glycerol, with a gas phase of $\mathrm{CO}_{2}+$ air (5:95); the temperature was $30^{\circ}$. The values indicate the amount of substrate utilized in the combined contents of two flasks, and the amounts of metabolites recovered, expressed in terms of moles of metabolite/mole of substrate used. Values for glucose metabolism of blood forms (at $37^{\circ}$ ) taken from Ryley (1956) are included for comparison.

\begin{tabular}{|c|c|c|c|c|c|c|}
\hline \multirow{6}{*}{$\begin{array}{l}\text { Amount of organism (mg. of } \mathrm{N} / 4 \mathrm{ml} . \text { ) } \\
\text { Incubation time (min.) } \\
\text { Substrate used ( } \mu \mathrm{moles})\end{array}$} & \multicolumn{2}{|c|}{ Blood form } & \multirow{2}{*}{\multicolumn{4}{|c|}{ Culture form }} \\
\hline & \multirow{2}{*}{$\begin{array}{l}\text { With } \\
\text { glucose }\end{array}$} & \multirow{3}{*}{$\begin{array}{c}\text { With } \\
\text { glycerol } \\
6 \cdot 30\end{array}$} & & & & \\
\hline & & & \multirow{2}{*}{\multicolumn{2}{|c|}{$\begin{array}{c}\text { With glucose } \\
\mathbf{4 \cdot 2 4}\end{array}$}} & \multirow{2}{*}{\multicolumn{2}{|c|}{$\begin{array}{c}\text { With glycerol } \\
\mathbf{3 \cdot 6 4}\end{array}$}} \\
\hline & - & & & & & \\
\hline & 60 & 30 & 75 & 150 & 50 & 150 \\
\hline & $21 \cdot 82$ & $33 \cdot 00$ & $15 \cdot 81$ & $17 \cdot 93$ & $19 \cdot 53$ & $46 \cdot 30$ \\
\hline \multicolumn{7}{|l|}{$\begin{array}{l}\text { Recovery of metabolites (moles/mole of } \\
\text { substrate used) }\end{array}$} \\
\hline Acid (bicarbonate) & $+1 \cdot 78$ & +0.87 & $+1 \cdot 18$ & -0.04 & $+1 \cdot 07$ & +0.80 \\
\hline $\mathrm{CO}_{2}$ & $+0 \cdot 13$ & +0.04 & $+3 \cdot 33$ & $+6 \cdot 32$ & +0.82 & $+1 \cdot 27$ \\
\hline $\mathrm{O}_{2}$ & $-1 \cdot 18$ & -0.90 & $-3 \cdot 60$ & $-6 \cdot 14$ & $-1 \cdot 61$ & -1.95 \\
\hline Pyruvic acid & +1.56 & +0.80 & 0.00 & 0.00 & 0.00 & 0.00 \\
\hline Glycerol & $+0 \cdot 38$ & $-1 \cdot 00$ & 0.00 & $0 \cdot 00$ & $-1 \cdot 00$ & $-1 \cdot 00$ \\
\hline Succinic acid & +0.02 & - & +0.06 & -0.34 & $+0 \cdot 15$ & $+0 \cdot 17$ \\
\hline Acetic acid & 0.00 & - & +0.09 & +0.31 & +0.30 & +0.28 \\
\hline R.Q. & $0 \cdot 11$ & 0.04 & 0.92 & $1 \cdot 03$ & 0.51 & 0.64 \\
\hline
\end{tabular}


Table 6. Metabolism of succinic acid by culture forms of Trypanosoma rhodesiense

Culture trypanosomes (about $4 \mathrm{mg}$. of $\mathrm{N}$ per flask) were incubated at $30^{\circ}$ for $2 \mathrm{hr}$. in three Dickens \& Simer manometer flasks each containing $2 \mathrm{ml}$. of Ringer-bicarbonate medium with $4 \mathrm{mg}$. of sodium succinate; the gas phase was $\mathrm{CO}_{2}+$ air (5:95). The values indicate the succinate used ( $\mu$ moles per flask) and the yields of various metabolic products expressed in terms of moles/mole of succinate utilized, and are the average of four experiments.

$\begin{array}{cccccc}\begin{array}{c}\text { Succinate } \\ \begin{array}{c}\text { used } \\ (\mu \text { moles })\end{array}\end{array} & \begin{array}{c}\text { Recovery of metabolites } \\ \text { (boles/mole of succinate used) }\end{array} & \text { Acetic } & \\ 8.75 & \mathrm{CO}_{2} & \mathrm{O}_{2} & \text { acid } & \text { R.Q. } \\ \text { (bicarbonate) } & +0.11 & +1.28 & -1.65 & +0.15 & 0.78\end{array}$

Table 7. Effect of inhibitors on the respiration of culture and blood forms of Trypanosoma rhodesiense

Each manometer flask contained trypanosomes (1-2 mg. of $\mathrm{N}$ ) in $1.2 \mathrm{ml}$. of Ringer-phosphate $20 \mathrm{mM}$ with respect to glucose; the gas phase was air; the temperature was $30^{\circ}$ for culture forms, $37^{\circ}$ for blood forms. In experiments with cyanide, balanced KOH-KCN mixtures were used in the centre wells as recommended by Robbie (1946). Inhibitor $(0.3 \mathrm{ml}$.) was added from the side bulb, and the respiratory inhibition estimated over a period of $1 \mathrm{hr}$. The results are expressed as percentage inhibition of normal respiration, and are averages of three to five determinations. Values for blood forms taken from Ryley (1956) are included for comparison.

$\begin{array}{lccc} & \begin{array}{c}\text { Concn. of } \\ \text { Inhibitor } \\$\cline { 3 - 3 } \text {$Inhibitor }\end{array} & \begin{array}{c}\text { Culture } \\ \text { form }\end{array} & \begin{array}{c}\text { Blood } \\ \text { form }\end{array} \\ & 3300 & 76 & 76 \\ & 1000 & 74 & 73 \\ & 330 & 74 & 67 \\ \text { Cyanide } & 100 & 68 & 33 \\ & 33 & 53 & 0 \\ & 460 & 83 & -14 \\ & 100 & 78 & -4 \\ & 46 & 68 & 4 \\ & 10 & 45 & -9 \\ & 4 \cdot 6 & 32 & -\end{array}$

Although succinate did not support as high a rate of respiration with culture forms as did glucose or glycerol (Table 1), these experiments indicate that it can be utilized. Table 6 summarizes a series of experiments in which succinate oxidation was studied. Small amounts of acetic acid accumulated, and about $30 \%$ of the carbon appeared as carbon dioxide; the fate of the rest of the succinate is unknown.

Respiratory inhibitors. The effect of cyanide and iodoacetate on respiration in the presence of glucose has been investigated (Table 7). Both forms showed a similar sensitivity to iodoacetate in high concentration, although at low concentrations the blood forms seemed more resistant to the compound. With cyanide, the respiration of blood forms was slightly stimulated; that of culture forms was markedly inhibited.

\section{Enzymic activities}

Cytochrome systems. In keeping with the lack of effect on respiration produced by cyanide, cytochrome pigments could not be detected spectroscopically in the blood forms of $T$. rhodesiense. Spectroscopic examination of suspensions of culture forms, however, self-reduced in the presence of glucose or reduced with sodium dithionite, showed an intense band at 553-570 $\mathrm{m} \mu$, a moderately strong band at $605 \mathrm{~m} \mu$ due to cytochrome $a$, and very faint $\beta$-bands at $530-537 \mathrm{~m} \mu$. No band due to cytochrome $c$ was evident, even when examined in the presence of $50 \%$ glycerol at the temperature of liquid nitrogen.

Catalase. Isolated trypanosomes were treated with the corresponding red-cell antiserum plus guinea-pig serum, and then exhaustively washed to ensure the complete removal of haemoglobin, before the preparation of homogenates to carry out the experiments illustrated in Fig. 1. Both forms showed catalatic activity, though the blood forms were the most active. At the lower homogenate concentrations, oxygen evolution never reached the theoretical maximum, indicating inactivation of the enzyme system responsible.

Dehydrogenases. By the method of Quastel \& Wheatley (1938), homogenates of both forms have been assayed for succinic dehydrogenase and lactic dehydrogenase. Table 8 indicates that succinic dehydrogenase was present in the culture forms, but that little lactic-dehydrogenase activity was demonstrable by this method. With blood forms, however, neither substrate gave carbon dioxide outputs in excess of the controls.

Phosphorylation of glucose and glycerol. Glucose and glycerol were utilized by intact cells, and were phosphorylated by cell homogenates at the expense of ATP (Fig. 2). During the experiment, more glycerol was utilized than glucose, and the rate of evolution of carbon dioxide was greater in the presence of glycerol, particularly with the culture forms. Most of the acid-labile phosphorus utilized became esterified, and there is a reasonable correspondence between glucose or glycerol disappearing and phosphorus esterified. 
Oxaloacetic decarboxylase. Although oxaloacetate at $\mathrm{pH} 5.0$ underwent spontaneous decarboxylation in the experiments described in Table 9, decarboxylation was enhanced in the presence of homogenates of both culture and blood-stream forms of $T$. rhodesiense.

\section{Spectrophotometric assays}

Many spectrophotometric assays have been carried out with NAD, $\mathrm{NADH}_{2}, \mathrm{NADP}$ and $\mathrm{NADPH}_{2}$ and a variety of substrates utilizing homogenates

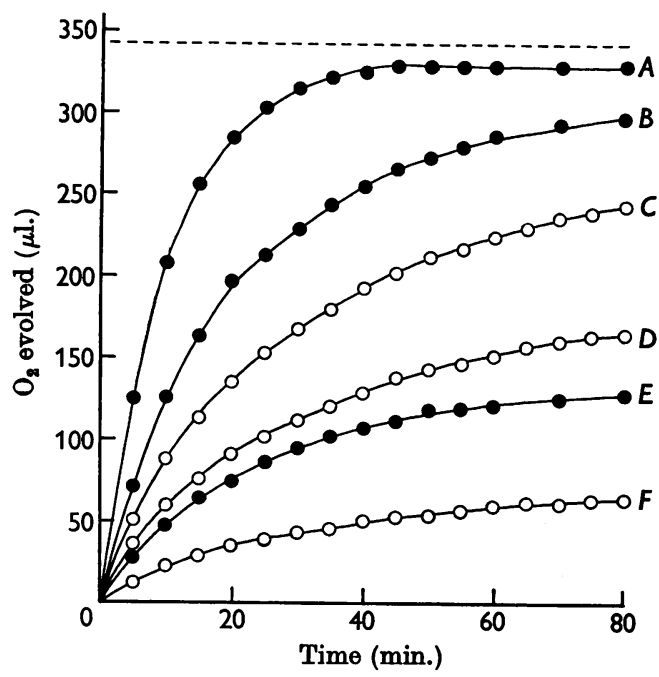

Fig. 1. Catalase activity in homogenates of culture and blood forms of Trypanosoma rhodesiense. Each manometer flask contained tris buffer, pH 7.3 (final concn. $0.13 \mathrm{M}$ ), and homogenate in the amounts indicated. Hydrogen peroxide $(30 \mu$ moles $)$ was added from the side bulb and the evolution of oxygen followed. The total vol. was $3 \mathrm{ml}$; the temperature was $30^{\circ}$. The broken line indicates the oxygen evolved from peroxide present by liver catalase. $O$, Culture form; 0 , blood form. The amount of homogenate (mg. of N) used was: $A, 1.98 ; B$, $0.99 ; C, 1.75 ; D, 1.05 ; E, 0.33 ; F, 0.35$.

\section{Table 8. Dehydrogenase activity in homogenates} of the culture form of Trypanosoma rhodesiense

Each manometer flask contained $\mathrm{NaHCO}_{3}$ (final conen. $20 \mathrm{~mm}), 0.2 \mathrm{ml}$. of $0.33 \mathrm{M}-\mathrm{K}_{3} \mathrm{Fe}(\mathrm{CN})_{6}$, succinate or lactate (final concn. $80 \mathrm{~mm}$ ), and homogenate $(5 \cdot 18 \mathrm{mg}$. of N) in a total vol. of 2.5 ml.; the gas phase was $\mathrm{CO}_{2}+\mathrm{N}_{2}(5: 95)$; the temperature was $30^{\circ}$. The rate of evolution of $\mathrm{CO}_{2}$ was estimated over the linear part of curve.

$\begin{array}{lc}\text { Substrate } & \begin{array}{c}\mathrm{CO}_{2} \text { evolution } \\ (\mu \mathrm{l} . / \mathrm{min} . / \mathrm{mg} . \text { of } \mathrm{N})\end{array} \\ \text { None } & \mathbf{0 \cdot 3 4} \\ \text { Succinate } & \mathbf{2 \cdot 2 4} \\ \text { Lactate } & \mathbf{0 . 4 1}\end{array}$

prepared on many different occasions (Table 10); some individual reactions are dealt with in more detail below.

Dihydronicotinamide-adenine dinucleotide oxidase and dihydronicotinamide-adenine dinucleotide phosphate oxidase. $\mathrm{NADPH}_{2}$ was reoxidized only to a very slight extent when incubated with homogenate in the absence of any other substrate (Table 10). $\mathrm{NADH}_{2}$ was slowly oxidized under similar conditions, the rate being just over twice as fast with culture as with blood forms; this may be contrasted with the fivefold difference in rate observed in manometric experiments with washed particle preparations rather than whole homogenates (Grant et al. 1961).

Glucose 6-phosphate dehydrogenase. Both culture and blood forms of $T$. rhodesiense show the same order of glucose 6-phosphate-dehydrogenase activity (Table 10). The enzyme required NADP, and no reaction took place when NAD was substituted. When NADP reduction was complete, the addition of oxaloacetate resulted in a partial reoxidation of $\mathrm{NADPH}_{2}$. There was a linear relationship between the initial rate of reaction and the enzyme concentration for two individual preparations of $T$. rhodesiense. An homogenate of the culture form was centrifuged at $1000 \mathrm{~g}$ for $15 \mathrm{~min}$. The supernatant was removed, and the particulate residue suspended in water and centrifuged again at $1000 \mathrm{~g}$ for $15 \mathrm{~min}$.; the washings were discarded and the residue was suspended in water to the original volume. Glucose 6-phosphate-dehydrogenase assays on the two fractions showed exactly twice the activity in the particulate fraction as in the soluble fraction, the same volume of each fraction being used for assay. In contrast with the marked glucose 6-phosphate-dehydrogenase activity, neither form of $T$. rhodesiense oxidized 6 phosphogluconic acid in the presence of NADP or NAD. Raw (1956) claimed that the culture form of Trypanosoma cruzi cleaved 6-phosphogluconate to triose phosphate plus pyruvate by the EntnerDoudoroff pathway. His system contained 6phosphogluconate, hydrazine, arsenite and $\mathrm{Mg}^{2+}$ ions; the reaction was followed by adding lactic dehydrogenase and $\mathrm{NADH}_{2}$ and following the decrease in absorption at $340 \mathrm{~m} \mu$ as pyruvate was formed and became reduced. With the same system, however, I could not demonstrate this pathway with homogenates of the culture forms of either $T$. cruzi or $T$. rhodesiense; $\mathrm{NADH}_{2}$ was indeed slowly oxidized, but the rate was no higher than that in the absence of 6-phosphogluconate, i.e. than the rate of dihydronicotinamide-adenine dinucleotide oxidase. Similarly, chemical estimations of pyruvic acid and alkali-labile phosphorus after incubation of $T$. cruzi homogenates with 6phosphogluconic acid in the presence of arsenite 
and hydrazine failed to demonstrate the EntnerDoudoroff cleavage.

$\alpha$-Glycerophosphate dehydrogenase. Although $\alpha$ glycerophosphate and NAD did not interact under the experimental conditions used, $\mathrm{NADH}_{2}$ was readily oxidized in the presence of triose phosphate; Table 10 indicates that this activity was greater in the blood forms, and this may be related to the importance of the $\alpha$-glycerophosphate-oxidase$\alpha$-glycerophosphate-dehydrogenase cycle in the terminal respiration of this form. Fructose 1,6diphosphate, after preincubation with homogenate, gave the same effect as triose phosphate, indicating the presence of aldolase in both culture and blood flagellates. Homogenates of both forms were separated into supernatant and particulate fractions as indicated above, and equal volumes of the whole homogenate or of either of the two fractions added to the system containing $\mathrm{NADH}_{2}$ and triose phosphate. With both forms, $\alpha$-glycerophosphate-dehydrogenase activity was mainly associated with the particulate component of the homogenate.

Attempts were made to demonstrate triose
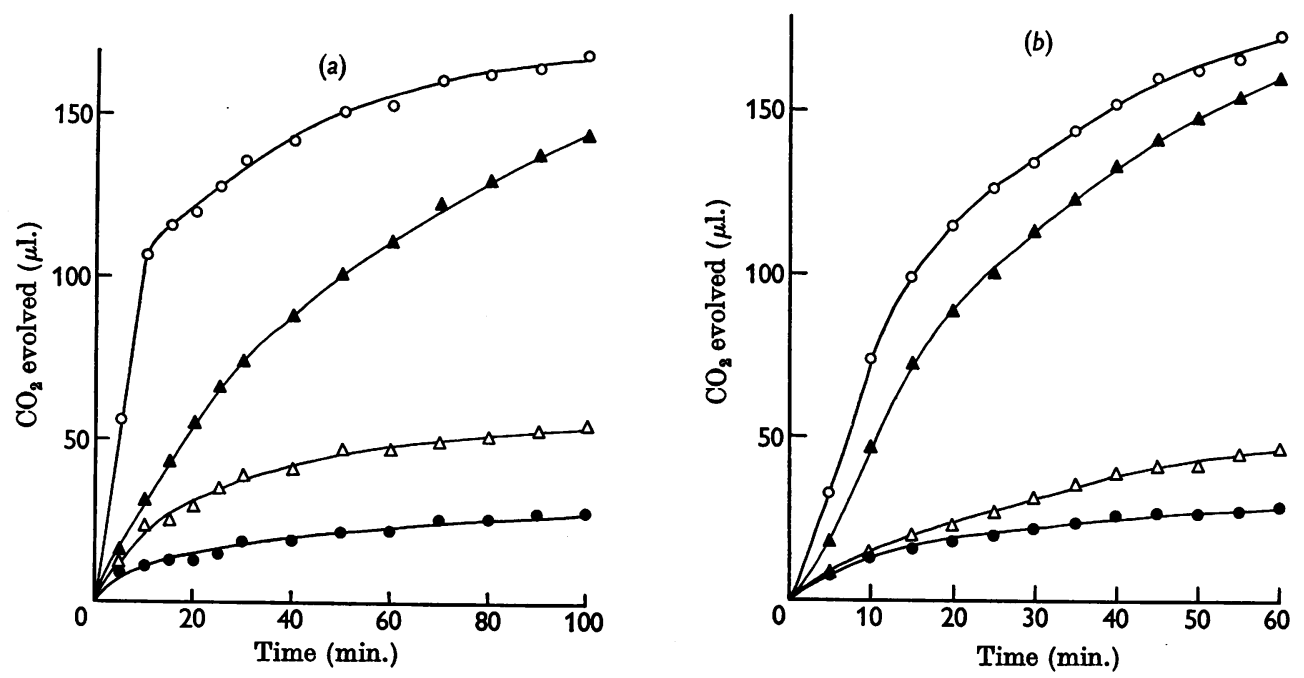

Fig. 2. Phosphorylation of glucose and glycerol by homogenates of culture and blood forms of Trypanosoma rhodesiense. Manometer flasks contained in $2.4 \mathrm{ml}$ : : $\mathrm{NaHCO}_{3}$ (final concn. $25 \mathrm{mM}$ ), $\mathrm{NaF}$ (final concn. $60 \mathrm{mM}$ ), $\mathrm{MgSO}_{4}$ (final concn. $5 \mathrm{mM}$ ), cysteine (final concn. $20 \mathrm{mM}$ ) and homogenate [(a) culture form $(0.98 \mathrm{mg}$. of $\mathrm{N})$; (b) blood form (1.1 mg. of $\mathrm{N})$ ]; the gas phase was $\mathrm{CO}_{2}+\mathrm{N}_{2}(5: 95)$; the temperature was $30^{\circ}$. ATP $(10 \mu$ moles $)$ and glucose or glycerol $(2 \mathrm{mg}$.) were added from the side bulb at the beginning of experiment: 0 , blank; $\triangle$, ATP alone; $\Delta$, glucose + ATP; O, glycerol + ATP. The reaction was stopped by adding $0.3 \mathrm{ml}$. of $2 \mathrm{~N}-\mathrm{H}_{2} \mathrm{SO}_{4}$ from a second side bulb. The manometer contents were neutralized; glucose or glycerol was estimated in $\mathrm{Ba}(\mathrm{OH})_{2}-\mathrm{ZnSO}_{4}$ filtrates and fructose and phosphate fractions in trichloroacetic acid filtrates as indicated below. $P_{0}$ represents the initial free inorganic phosphate, and $P_{7}$ and $P_{180}$ the total inorganic phosphate present after hydrolysis in $\mathrm{N}-\mathrm{HCl}$ at $100^{\circ}$ for 7 and $180 \mathrm{~min}$. respectively. The values represent the $\mu$ moles used $(-)$ or formed $(+)$.

\begin{tabular}{|c|c|c|c|}
\hline Substrate & Assays & Culture form & Blood form \\
\hline Glucose & $\begin{array}{l}\text { Glucose } \\
\text { Acid (bicarbonate) } \\
\text { Fructose 6-phosphate } \\
\mathbf{P}_{7}-\mathbf{P}_{0} \\
\mathbf{P}_{0} \\
\mathbf{P}_{180}-P_{7}\end{array}$ & $\begin{array}{l}-5 \cdot 82 \\
+6 \cdot 43 \\
+1 \cdot 74 \\
-6 \cdot 34 \\
+1 \cdot 05 \\
+0 \cdot 81\end{array}$ & $\begin{array}{l}-6 \cdot 52 \\
+7 \cdot 15 \\
+2 \cdot 85 \\
-5 \cdot 65 \\
-0 \cdot 18 \\
+2 \cdot 07\end{array}$ \\
\hline Glycerol & $\begin{array}{l}\text { Glycerol } \\
\text { Acid (bicarbonate) } \\
\mathbf{P}_{7}-\mathbf{P}_{0} \\
\mathbf{P}_{\mathbf{0}} \\
\mathbf{P}_{\mathbf{1 8 0}}-\mathbf{P}_{7}\end{array}$ & $\begin{array}{r}-8 \cdot 66 \\
+7 \cdot 54 \\
-8 \cdot 05 \\
0.00 \\
0.00\end{array}$ & $\begin{array}{l}-8 \cdot 83 \\
+7 \cdot 73 \\
-7 \cdot 70 \\
-0 \cdot 76 \\
+0 \cdot 66\end{array}$ \\
\hline None & $\begin{array}{l}\text { Acid (bicarbonate) } \\
P_{7}-P_{0} \\
P_{0}\end{array}$ & $\begin{array}{l}+2 \cdot 46 \\
-2 \cdot 34 \\
+2 \cdot 24\end{array}$ & $\begin{array}{l}+2 \cdot 10 \\
-1 \cdot 73 \\
+1 \cdot 82\end{array}$ \\
\hline
\end{tabular}


phosphate dehydrogenase by incubating homogenate with fructose diphosphate and NAD in the presence of arsenate and a cysteine-pyrophosphate buffer; no overall reduction of NAD took place, however, and it is possible that any $\mathrm{NADH}_{2}$ generated by triose phosphate oxidation was immediately utilized by the very active $\alpha$-glycerophosphate dehydrogenase.

Malic enzymes. Homogenates of the culture form of $T$. rhodesiense readily reduced NADP in the presence of malate, but there was no reduction of NAD either at $\mathrm{pH} \mathbf{7 \cdot 3}$ or at $\mathrm{pH} 9 \cdot 0$. Similarly,

Table 9. Oxaloacetic-decarboxylase activity in homogenates of the culture and blood forms of Trypanosoma rhodesiense

Each manometer flask contained homogenate in the amount indicated, $\mathrm{MnCl}_{2}$ (final concn. $1 \mathrm{mM}$ ) and acetate buffer, pH 5.0 (final concn. $25 \mathrm{~mm}$ ). Oxaloacetate $(15 \mu$ moles) at pH 5.0 was added from the side bulb and the evolution of $\mathrm{CO}_{2}$ followed; the final vol. was $2 \mathrm{ml}$; the temperature was $30^{\circ}$. The values represent the evolution of $\mathrm{CO}_{2}$ observed over the first $6 \mathrm{~min}$. (linear part of curve).

$\begin{array}{lcc}\begin{array}{c}\text { Form of } \\ \text { organism }\end{array} & \begin{array}{c}\text { Amount of } \\ \text { homogenate } \\ \text { (mg. of } \mathrm{N})\end{array} & \begin{array}{c}\mathrm{CO}_{2} \\ \text { evolved } \\ (\mu \mathrm{l} .)\end{array} \\ \text { None } & - & 59 \\ \text { Culture } & 1.98 & 306 \\ & 0.66 & 234 \\ \text { Blood } & 0.22 & 124 \\ & 2.43 & 246 \\ & 0.81 & 171 \\ & 0.27 & 91\end{array}$

homogenates of the culture form of T. cruzi reduce NADP but not NAD at $\mathrm{pH} \mathrm{7.3}$ or 9.0 in the presence of malate (see Baernstein, 1952, $1953 a, b$ ). This activity, coupled with the oxaloacetic-decarboxylase activity described above, indicates the presence of malic enzyme in these homogenates. Although whole cells of the blood form of $T$. rhodesiense, in contrast with the culture form, do not fix carbon dioxide, homogenates readily reduce NADP in the presence of malate; this takes place at about $40 \%$ of the rate of the culture forms when assayed at the same temperature (Table 10). With one particular preparation of the culture form, rates of 0.316 and $0.459 \mu \mathrm{mole} / \mathrm{mg}$. of $\mathrm{N} / \mathrm{min}$. were observed at $\mathrm{pH} 7.3$ and 9.0 respectively, both in tris buffer. With the same fractionated homogenate mentioned above in connexion with glucose 6phosphate-dehydrogenase activity, eight times as much malic-enzyme activity was present in the supernatant as in the particulate fraction of the homogenate. The reaction between NADP and malate has also been shown manometrically. An homogenate of the culture form was incubated in a carbon dioxide-bicarbonate buffer in the presence of $\mathrm{Mn}^{2+}$ ions, malate and NADP, and the evolution of carbon dioxide was followed. The bulk of the evolution of carbon dioxide took place during the first $10 \mathrm{~min}$., but the incubation was continued for $30 \mathrm{~min}$. before the reaction was stopped by the addition of acid. Analysis of initial and final samples showed the production of equivalent amounts of pyruvate and carbon dioxide (Table 11).

Table 10. Spectrophotometric assays with homogenates of culture and blood forms of Trypanosoma rhodesiense

Each cuvette contained in $3 \mathrm{ml}$ : tris buffer, pH 7.3 (final concn. $40 \mathrm{~mm}$ ), $0 \cdot 23 \mu$ mole of $\mathrm{NAD} \mathrm{NADH}_{2}$, NADP or $\mathrm{NADPH}_{2}$, substrate (final concn. $5 \mathrm{~mm}$ ), and homogenate. The reactions were followed at $340 \mathrm{~m} \mu$, and the initial reaction rates calculated, usually over the first minute. The values are average rates ( $\mu \mathrm{mole} / \mathrm{min} . /$ mg. of N) observed, and the number of estimations and the range are given in parentheses. Preparations marked * were dialysed before use.

NAD

NAD + lactate

NAD + malate

$\mathrm{NADH}_{2}$

$\mathrm{NADH}_{2}+$ triose phosphate

$\mathrm{NADH}_{2}$ + oxaloacetate

$\mathrm{NADH}_{2}+$ pyruvate

$\mathrm{NADH}_{2}$

$\left\{\mathrm{NADH}_{2}+\right.$ lipoate (oxidized)

NADP

NADP + malate

NADP + isocitrate

NADP + glucose 6-phosphate

NADP + 6-phosphogluconato

$\mathrm{NADPH}_{2}$

$\mathrm{NADPH}_{2}$ + oxaloacetate

$\mathrm{NADPH}_{2}+$ pyruvate
Initial reaction rate

\begin{tabular}{ll}
\hline \multicolumn{1}{c}{ Culture form } & \multicolumn{1}{c}{ Blood form } \\
$0.000(2)$ & $0.000(2)$ \\
$0.000(2)$ & $0.000(3)$ \\
$0.000(2)$ & $0.000(2)$ \\
$0.052(28 ; 0.017-0.090)$ & $0.023(13 ; 0.010-0.035)^{*}$ \\
$0.310(8 ; 0.171-0.498)$ & $0.470(11 ; 0.119-0.691)^{*}$ \\
$0.990(9 ; 0.638-1.332)$ & $0.220(9 ; 0.140-0.359)^{*}$ \\
$0.074(10 ; 0.052-0.143)$ & $0.096(8 ; 0.027-0.190)^{*}$ \\
$0.024(5 ; 0.015-0.035)^{*}$ & $0.014(3 ; 0.007-0.018)^{*}$ \\
$0.041(8 ; 0.020-0.081)^{*}$ & $\left\{0.028(4 ; 0.009-0.038)^{*}\right.$ \\
$0.000(2)$ & $0.001(3 ; 0.000-0.001)$ \\
$0.327(15 ; 0.218-0.441)$ & $0.130(15 ; 0.098-0.191)$ \\
$0.141(18 ; 0.101-0.208)$ & $0.039(12 ; 0.025-0.059)$ \\
$0.063(15 ; 0.028-0.090)$ & $0.066(9 ; 0.044-0.105)$ \\
$0.003(4 ; 0.000-0.009)$ & $0.000(2)$ \\
$0.009(10 ; 0.000-0.023)$ & $0.006(4 ; 0.001-0.012)^{*}$ \\
$0.030(7 ; 0.020-0.054)$ & $0.029(4 ; 0.010-0.050)^{*}$ \\
$0.018(2 ; 0.014-0.022)$ & $0.002(2 ; 0.001-0.003)^{*}$
\end{tabular}


Although malate would not bring about the reduction of NAD in the presence of homogenate, $\mathrm{NADH}_{2}$ and oxaloacetate interacted with homogenates of both forms (Table 10); the reaction with homogenates of the culture form was the fastest of all the spectrophotometric assays carried out. Oxaloacetate also caused oxidation of $\mathrm{NADPH}_{2}$, although at a much lower rate, which was the same for both forms of the flagellate (Table 10).

The reactions involving malate may be associated with succinic acid formation by whole cells of the culture form. Although succinic dehydrogenase has been demonstrated in the culture form by ferricyanide reduction (Table 8) and by the use of phenazine methosulphate (Grant et al. 1961), it has not been possible, with homogenates of either form, to demonstrate spectrophotometrically the reduction of cytochrome $c$ in the presence of succinate, nor has the cytochrome $c$ band been observed spectroscopically, although this does not exclude the presence of a low concentration of the pigment. Attempts have been made to obtain oxaloacetate (which would be measured spectrophotometrically by its reaction with $\mathrm{NADH}_{2}$ ) by incubating homogenates with phosphoenolpyruvate and bicarbonate in the presence of $\mathrm{ADP}$ and ITP, but without success. Likewise unsuccessful were attempts to observe manometrically the fixation of carbon dioxide and the formation of acid by homogenates supplied with pyruvate, ATP and glucose 6-phosphate plus NADP (as a source of $\mathrm{NADPH}_{2}$ ) in a carbon dioxide-bicarbonate buffer.

Dihydronicotinamide-adenine dinucleotide-cytochrome c reductase. When homogenates of either form were incubated with $\mathrm{NADH}_{2}$ and cytochrome $c$ in the presence of cyanide, no change in absorption at $550 \mathrm{~m} \mu$ was observed.

Lactic dehydrogenase. Little evolution of carbon dioxide in excess of the control took place in the presence of lactate, as shown by the ferricyanide assay (Table 8). Spectrophotometrically, however, although no reaction has been demonstrated

\section{Table 11. Malic enzyme in homogenates of the} culture forms of Trypanosoma rhodesiense

Each manometer flask contained homogenate in the amount indicated, with $20 \mu$ moles of malate, $10 \mu$ moles of NADP and $1.5 \mu$ moles of $\mathrm{MnCl}_{2}$, in $1.5 \mathrm{ml}$. of Ringerbicarbonate; the gas phase was $\mathrm{CO}_{2}+$ air (5:95). The incubation was carried out for $30 \mathrm{~min}$. at $30^{\circ}$.

$\begin{array}{ccc}\begin{array}{c}\text { Amount of } \\ \text { homogenate } \\ (\mathrm{mg} . \text { of } \mathrm{N})\end{array} & \begin{array}{c}\text { Pyruvate } \\ \text { produced } \\ (\mu \mathrm{moles})\end{array} & \begin{array}{c}\mathrm{CO}_{2} \\ \text { evolved } \\ (\mu \mathrm{moles})\end{array} \\ 2 \cdot 09 & 6 \cdot 13 & 5 \cdot 32 \\ 0 \cdot 70 & 5 \cdot 48 & 5 \cdot 27 \\ 0.23 & 3.46 & 3 \cdot 58\end{array}$

between NAD and lactate, pyruvate stimulated the oxidation of $\mathrm{NADH}_{2}$ by homogenates of both blood and culture flagellates (Table 10), suggesting that lactic dehydrogenase may be present.

Dihydronicotinamide-adenine dinucleotide-lipoate reductase. Grant (1962) reported that lipoate could be reduced at the expense of $\mathrm{NADH}_{2}$ by preparations of blood-stream forms. Table 10 includes results obtained in several assays with dialysed homogenates from three batches of both blood and culture forms. Although there is a fairly wide variation in the rates observed with different preparations, oxidized lipoate does increase the rate of oxidation of $\mathrm{NADH}_{2}$ by both forms.

Isocitric dehydrogenase. Homogenates of the culture form of $T$. rhodesiense readily catalysed the reduction of NADP in the presence of isocitrate and $\mathrm{Mn}^{2+}$ ions (Table 10); no marked reaction took place when NAD was substituted. The same reaction was found in homogenates of the blood form, although here the rate was considerably less. In either case, $\mathrm{NADPH}_{2}$ formed during this reaction could be partially reoxidized by the addition of oxaloacetate.

Fumarase and aconitase. Fumarase was shown in homogenates of culture trypanosomes by following the decrease in absorption at $300 \mathrm{~m} \mu$ in the presence of fumarate; no increase in absorption at this wavelength took place, however, in the presence of citrate or isocitrate. A more convenient way to demonstrate these enzymes, qualitatively at least, is illustrated in Table 12. Concentrations of homogenate were selected which brought about a satisfactory reduction of NADP in the presence of malate or isocitrate over a $7 \mathrm{~min}$. experimental period. When fumarate, citrate or cis-aconitate was used instead, the reduction rate was smaller, particularly with citrate or cisaconitate and homogenates of blood-stream forms. If, however, substrate and homogenate were preincubated before the addition of NADP, the reaction rate was greater, depending on the time of preincubation and the activity of the fumarase or aconitase present. Both forms contain an active fumarase; the activity of aconitase, which is present in both cases, is particularly low in the blood-stream forms.

Pyruvic oxidase. A spectrophotometric test for pyruvic oxidase was carried out as suggested by Korkes (1955). Homogenates of the culture form brought about a reduction of NAD in a system containing GSH, cocarboxylase, CoA and pyruvate (Fig. 3). When cocarboxylase, CoA or pyruvate was omitted, there was a gradual decrease in absorption at $340 \mathrm{~m} \mu$, but if the missing reactant were then added, NAD reduction took place; Fig. 3 illustrates the effect obtained by omitting CoA from the initial mixture. In the absence of 
Table 12. Fumarase and aconitase activities of homogenates of the culture and blood forms of Trypanosoma rhodesiense

Each cuvette contained in $3 \mathrm{ml}$ : tris buffer, $\mathrm{pH} 7 \cdot 3$ (final concn. $40 \mathrm{~mm}$ ), $\mathrm{MnCl}_{2}$ (final concn. $1 \mathrm{mM}$ ), substrate (final concn. $5 \mathrm{mM}$ ), and homogenate. The reaction was started by adding $0.23 \mu$ mole of NADP after the preincubation period indicated.

\begin{tabular}{|c|c|c|c|c|}
\hline $\begin{array}{l}\text { Form of } \\
\text { organism }\end{array}$ & $\begin{array}{c}\text { Amount of } \\
\text { homogenate } \\
\text { (mg. of } N \text { ) }\end{array}$ & Substrate & $\begin{array}{c}\text { Preincubation } \\
\text { time } \\
\text { (min.) }\end{array}$ & $\begin{array}{c}\text { Rate of NADP } \\
\text { reduction } \\
\text { ( } \mu \text { mole } / \mathrm{min} . / \\
\mathrm{mg} . \text { of } \mathrm{N})\end{array}$ \\
\hline Culture & 0.18 & $\begin{array}{l}\text { Malate } \\
\text { Fumarate } \\
\text { Fumarate } \\
\text { Fumarate }\end{array}$ & $\begin{array}{r}0 \\
0 \\
8 \\
16\end{array}$ & $\begin{array}{l}0 \cdot 334 \\
0 \cdot 109 \\
0 \cdot 246 \\
0 \cdot 321\end{array}$ \\
\hline Blood & 0.52 & $\begin{array}{l}\text { Malate } \\
\text { Fumarate } \\
\text { Fumarate } \\
\text { Fumarate }\end{array}$ & $\begin{array}{r}0 \\
0 \\
4 \\
16\end{array}$ & $\begin{array}{l}0 \cdot 128 \\
0 \cdot 020 \\
0 \cdot 043 \\
0 \cdot 115\end{array}$ \\
\hline Culture & 0.50 & $\begin{array}{l}\text { Isocitrate } \\
\text { Citrate } \\
\text { Citrate } \\
\text { Citrate } \\
\text { cis-Aconitate } \\
\text { cis-Aconitate } \\
\text { cis-Aconitate }\end{array}$ & $\begin{array}{l}0 \\
0 \\
2 \\
8 \\
0 \\
2 \\
4\end{array}$ & $\begin{array}{l}0.129 \\
0.012 \\
0.051 \\
0 \cdot 106 \\
0 \cdot 045 \\
0 \cdot 100 \\
0 \cdot 121\end{array}$ \\
\hline Blood & $1 \cdot 14$ & $\begin{array}{l}\text { Isocitrate } \\
\text { Citrate } \\
\text { Citrate } \\
\text { Citrate } \\
\text { cis-Aconitate } \\
\text { cis-Aconitate } \\
\text { cis-Aconitate }\end{array}$ & $\begin{array}{r}0 \\
0 \\
16 \\
120 \\
0 \\
8 \\
32\end{array}$ & $\begin{array}{l}0.046 \\
0.000 \\
0.005 \\
0.028 \\
0.006 \\
0.013 \\
0.028\end{array}$ \\
\hline
\end{tabular}

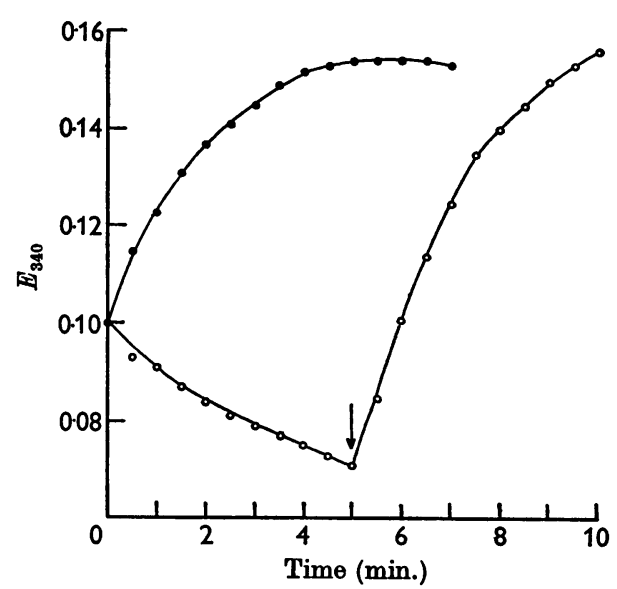

Fig. 3. Pyruvic-oxidase activity of homogenates of the culture form of Trypanosoma rhodesiense. Each cuvette contained in $3 \mathrm{ml}$ : $200 \mu$ moles of potassium phosphate

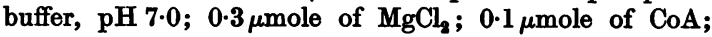
$0.4 \mu$ mole of NAD; $10 \mu$ moles of GSH; $0.2 \mu$ mole of cocarboxylase; $5 \mu$ moles of potassium pyruvate; homogenate $(0.55 \mathrm{mg}$. of $\mathrm{N})$. O, Complete system; $\mathrm{O}, \mathrm{CoA}$ omitted initially and added at the time indicated by the arrow.

GSH, the rate and extent of NAD reduction was considerably decreased but not abolished. Prolonged incubation of the complete system showed a gradual reduction of NAD to a peak value, maintenance of this level of absorption for 2-3 min., and then a gradual reoxidation of the $\mathrm{NADH}_{2}$. Dialysed homogenates showed pyruvicoxidase activity in the same way. In contrast, neither dialysed nor non-dialysed homogenates of blood-stream trypanosomes showed any pyruvicoxidase activity.

Transhydrogenase. Glucose or glycerol metabolism as far as the pyruvic acid stage involves the formation of $\mathrm{NADH}_{2}$. Under aerobic conditions this may be reoxidized through the cytochrome or $\alpha$-glycerophosphate systems, but anaerobically glycerol accumulates with blood-stream trypanosomes, and succinate with culture forms. It would seem reasonable to assume that succinate formation involves the malic enzyme, and this requires $\mathrm{NADPH}_{2}$ for activity. Attempts have therefore been made to find a system which would carry out the reaction:

$$
\mathrm{NADH}_{2}+\mathrm{NADP} \rightleftharpoons \mathrm{NAD}+\mathrm{NADPH}_{2}
$$

and so couple the two stages of anaerobic glucose or glycerol metabolism in culture trypanosomes.

A commercial preparation of lactic dehydrogenase caused the reduction of NAD in the presence of lactate at $\mathrm{pH} 10$, and correspondingly less extensive reduction at lower $\mathrm{pH}$; at $\mathrm{pH} \mathbf{8 . 5}$ the final extinction was about half maximal. 
Lactate, lactic dehydrogenase and a small amount of NAD were incubated at $\mathrm{pH} 8.5$ until NAD reduction had finished. NADP and culture trypanosome homogenate were then added, but there was no further reduction of nucleotide. Although the lactic dehydrogenase was specific for NAD, if transhydrogenase had been present, lactate could have brought about the reduction of NADP in the presence of catalytic quantities of NAD.

$\mathrm{NADPH}_{2}$ is oxidized much more slowly than $\mathrm{NADH}_{2}$ by homogenates of the culture form (Table 10); the addition of NAD to a system containing $\mathrm{NADPH}_{2}$ and homogenate did not increase the rate of oxidation as might have been expected had there been a transhydrogenase present capable of transferring hydrogen from $\mathrm{NADPH}_{2}$ to $\mathrm{NAD}$. Similarly the reaction rate of oxaloacetate with $\mathrm{NADPH}_{2}$ was not increased by the addition of NAD, although the reaction between oxaloacetate and $\mathrm{NADH}_{2}$ was rapid.

NADP was readily reduced by culture homogenates in the presence of isocitrate (Table 10); little reaction took place when NAD was substituted for NADP. When, however, a small amount of NADP was first added to the system and the reduction was followed to completion, and NAD then added, there was a slow increase in

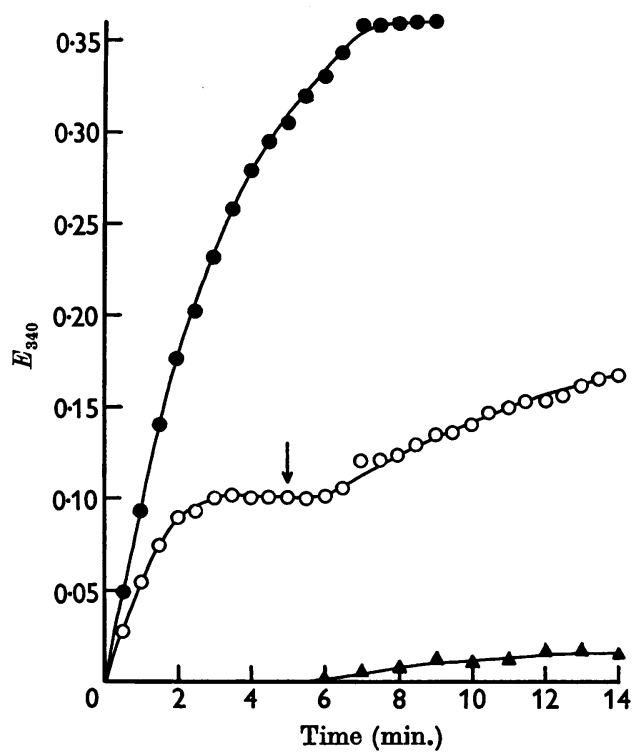

Fig. 4. Transhydrogenase activity in homogenates of the culture form of Trypanosoma rhodesiense. Each cuvette contained in $3 \mathrm{ml}$.: tris buffer, $\mathrm{pH} 7 \cdot 3$ (final concn. $40 \mathrm{~mm}$ ), $\mathrm{MnCl}_{2}$ (final concn. $1 \mathrm{~mm}$ ), isocitrate (final concn. $5 \mathrm{~mm}$ ) and homogenate $(0.65 \mathrm{mg}$. of N). $0,0.23 \mu$ mole of NADP added initially; $O, 0.08 \mu$ mole of NADP added initially followed by $0.23 \mu$ mole of NAD at the time indicated by the arrow; $\triangle, 0 \cdot 23 \mu$ mole of NAD added initially. absorption which could be explained by the presence of transhydrogenase in the homogenate (Fig. 4). Likewise glucose 6-phosphate could be used to bring about the reduction of $\mathrm{NADP}$, but no reaction at all took place with NAD. When, however, NAD was added after the reduction of a small amount of NADP, a slow increase in absorption took place. Similar effects were observed with dialysed homogenates of blood-stream trypanosomes.

\section{DISCUSSION}

Trypanosomes have intense motility, which nevertheless results in little translatory movement. This activity in most species studied requires an extracellular source of energy. Suitable substrates for $T$. rhodesiense are limited (Table 1), especially for the blood-stream forms. Utilization of glucose, which would seem to be the most important natural source of energy, is with most species incomplete, resulting in the production of various organic acids, glycerol or ethanol (Ryley, 1956). In the bloodstream forms of the brucei group, glucose breakdown does not proceed beyond the pyruvic acid stage (Reiner, Smythe \& Pedlow, 1936; Harvey, 1949; Ryley, 1956). Brand et al. (1955) showed that, during growth in culture of $T$. gambiense, acetic acid, succinic acid, lactic acid and pyruvic acid accumulated in the medium; of the volatile acids produced, fractionation indicated $98.3 \%$ to be acetic acid. In short-term experiments, the R.Q. was 0.97 . With $T$. rhodesiense in washed suspension, and carrying out the experiments in the presence of carbon dioxide, I have never found more than traces of lactic acid or pyruvic acid, but have found succinic acid and volatile acid (assumed to be acetic acid), especially under anaerobic conditions. Under aerobic conditions, the culture forms of $T$. rhodesiense carry the breakdown of glucose or of glycerol almost to completion, and the amount of organic acid accumulating is small; utilization appears to take place in two phases : an initial rapid breakdown of substrate and a second phase during which respiration continues at the expense of accumulated intermediates. This is similar to the observation of Chang (1948) with $T$. cruzi growing in culture.

The present studies indicate differences in response to cyanide of the two forms of $T$. rhodes iense and include results on the absorption bands due to cytochrome pigments. Homogenates of culture forms oxidized $p$-phenylenediamine, but these experiments have not been reported in detail since similar effects were found with bloodstream forms, and the interpretation of the experiments is ambiguous (Ryley, 1956; Fulton \& Spooner, 1959). Although the blood-stream trypanosomes of the brucei group do not contain 
cytochrome pigments, they are able to respire actively utilizing the $\alpha$-glycerophosphate-oxidase$\alpha$-glycerophosphate-dehydrogenase system described by Grant \& Sargent (1960). The relative importance of some oxidase systems in several blood and culture forms of trypanosome has been described by Grant et al. (1961).

Although the overall carbohydrate metabolism and the respiratory systems differ markedly between the two forms of $T$. rhodesiense, the cell homogenates have many enzymes in common. Thus both contain hexokinase, glycerol kinase, aldolase, $\alpha$-glycerophosphate dehydrogenase and $\mathbf{a}$ NADP-linked glucose 6-phosphate dehydrogenase. The function of this latter enzyme in the trypanosome is obscure. However, enzymes concerned with metabolism beyond the pyruvate stage are present in blood-stream as well as culture trypanosomes; the activities of some of these are lower for the blood forms (Table 10), but all assays were carried out at room temperature $\left(20^{\circ}\right)$; although culture forms grow around this temperature, the blood forms normally live at $37^{\circ}$, at which temperature the systems will have greater activity. The failure of blood-stream trypanosomes to carry carbohydrate breakdown beyond the pyruvic acid stage is therefore due to the lack of just one or two enzymes. Thus pyruvic-oxidase activity has not been detected in blood-stream trypanosomes, but it is found in culture forms. Similarly aconitase activity in the blood forms is decreased to a very low level.

Succinate formation, especially under anaerobic conditions, is common to several trypanosomes (Ryley, 1956), and is evidently a mechanism for maintaining the oxido-reduction balance in the absence of oxygen. The blood-stream form of $T$. rhodesiense in common with other members of the brucei group produces glycerol to maintain this balance, whereas Strigomonas oncopelti (Ryley, 1955) and Trypanosoma mega (J. F. Ryley, unpublished work) form ethanol; overall metabolism in these cases involves the reduction and reoxidation of NAD. With trypanosomes which produce succinate, however, it is generally accepted that $\mathrm{NADH}_{2}$ is produced during degradation to the pyruvic acid level, whereas succinate formation is considered to involve the utilization of $\mathrm{NADPH}_{2}$. The present work does not offer convincing evidence for the presence of transhydrogenase to link the functioning of the two nucleotides, since, although some methods indicated the activity of such an enzyme, others did not. Raw (1956) tried to explain succinic acid production by $T$. cruzi with the Entner-Doudoroff pathway in terms of the reduction and reoxidation of NADP. His evidence was neither detailed nor convincing, and we could not repeat it with culture forms of either
T. cruzi or T. rhodesiense. Such a pathway would explain the presence of glucose 6-phosphate dehydrogenase in both organisms, but the other enzymes required seem to be absent. Glycerol metabolism by trypanosomes was therefore examined, since if succinate were produced from glycerol it would hardly be formed by a pathway involving $\mathrm{C}_{6}$ compounds. $T$. cruzi did not utilize glycerol, but culture forms of $T$. rhodesiense converted glycerol almost entirely into succinate under anaerobic conditions. The conversion of pyruvate into malate may involve a carboxylation to oxaloacetate, followed by the reduction of oxaloacetate with $\mathrm{NADH}_{2}$; the latter reaction was in fact the most vigorous of the reactions that were measured spectrophotometrically.

To correlate further metabolic differences with the various stages of the life-cycle, it will be necessary either to devise procedures for cultivating each stage in reasonable quantities in vitro, or alternatively to reduce the scale of the experiments and use histochemical procedures with the limited numbers of trypanosomes obtainable from tsetse flies. In connexion with this correlation between metabolism and morphology, Vickerman (1962), using the electron microscope, has found a much more highly developed mitochondrial system in the culture form of $T$. rhodesiense than in the bloodstream stage.

\section{SUMMARY}

1. The motility and respiration of the bloodstream and culture forms of Trypanosoma rhodesiense depend on a supply of extracellular substrate; both can utilize glycerol, glucose, fructose and mannose, whereas the culture forms can also utilize some tricarboxylic acid-cycle intermediates, especially under acid conditions.

2. Culture forms oxidize glucose or glycerol with a high R.Q., mainly to carbon dioxide with small amounts of acetic acid and succinic acid; under anaerobic conditions they convert them into succinic acid and acetic acid with a net assimilation of carbon dioxide, which is essential for anaerobic metabolism. Blood-stream forms convert glucose or glycerol mainly into pyruvic acid and the R.Q. is low; in addition glycerol is formed from glucose under anaerobic conditions.

3. The respiration of culture forms is sensitive to cyanide, though that of blood-stream forms is not; cytochrome pigments have been detected spectroscopically in culture but not blood-stream forms.

4. Cell-free preparations of both forms show hexokinase, glycerol-kinase, $\alpha$-glycerophosphate-dehydrogenase, aldolase, lactic-dehydrogenase, oxaloacetic-decarboxylase, malic-dehydrogenase (NADlinked), malic-enzyme (NADP-linked), isocitric- 
dehydrogenase and glucose 6-phosphate-dehydrogenase activity; both contain fumarase and aconitase, although aconitase activity is particularly low in the blood-stream form. Culture trypanosomes show pyruvic-oxidase activity, whereas blood-stream forms do not. Attempts to demonstrate transhydrogenases have been inconclusive.

I thank Mrs Winifred Jones and her colleagues for the preparation of the large quantities of medium involved.

\section{REFERENCES}

Archibald, A. R., Hirst, E. L., Manners, D. J. \& Ryley, J. F. (1960). J. chem. Soc. p. 556.

Ashcroft, M. T. (1960). Ann. trop. Med. Parasit. 54, 44.

Baernstein, H. D. (1952). Fed. Proc. 11, 183.

Baornstein, H. D. (1953a). Exp. Parasit. 2, 380.

Baernstein, H. D. (1953b). Ann. N.Y. Acad. Sci. 56, 982.

Brand, T. von \& Johnson, E. M. (1947). J. cell. comp. Physiol. 29, 33.

Brand, T. von, Weinbach, E. C. \& Tobie, E. J. (1955). J. cell. comp. Physiol. 45, 421.

Buchanan, J. M., Sakami, W., Gurin, S. \& Wilson, D. W. (1947). J. biol. Chem. 169, 403.

Chang, S. L. (1948). J. infect. Dis. 82, 109.

Fulton, J. D. \& Spooner, D. F. (1959). Exp. Parasit. 8, 137.
Gordon, R. M. \& Miller, J. K. (1961). Nature, Lond., 191, 1317.

Grant, P. T. (1962). Ann. trop. Med.Parasit. (In the Press.) Grant, P. T. \& Sargent, J. R. (1960). Biochem. J. 76, 229. Grant, P. T., Sargent, J. R. \& Ryley, J. F. (1961). Biochem. J. 81, 200.

Harvey, S. C. (1949). J. biol. Chem. 179, 435.

Korkes, S. (1955). In Methods in Enzymology, vol. 1, p. 485. Ed. by Colowick, S. P. \& Kaplan, N. O. New York: Academic Press Inc.

Ormerod, W. E. (1958). J. gen. Microbiol. 19, 271.

Ormerod, W. E. (1961). Trans. R. Soc. trop. Med. Hyg. 55, 313.

Quastel, J. H. \& Wheatley, A. H. M. (1938). Biochem. J. 32, 936.

Raw, I. (1956). Ciênc. e Cult. 8, 245.

Reiner, L., Smythe, C. V. \& Pedlow, J. T. (1936). J. biol. Chem. 118, 75.

Robbie, W. A. (1946). J. cell. comp. Physiol. 27, 181.

Ryley, J. F. (1955). Biochem. J. 59, 353.

Ryley, J. F. (1956). Biochem. J. 62, 215.

Ryley, J. F. (1961a). Ann. trop. Med. Parasit. 55, 149.

Ryley, J. F. (1961b). Abstr. 1st int. Conf. Protozool., Prague, p. 182.

Tobie, E. J., Brand, T. von \& Mehlman, B. (1950). J. Parasit. 36, 48.

Trager, W. (1959). Ann. trop. Med. Parasit. 53, 473.

Vickerman, K. (1962). Trans. R. Soc. trop. Med. Hyg. (In the Press.)

\title{
Studies on the Chemical Basis of the Antigenicity of Proteins
}

\section{SYNTHESIS, CHARACTERIZATION AND IMMUNOGENICITY OF SOME MULTICHAIN AND LINEAR POLYPEPTIDES CONTAINING TYROSINE*}

\author{
BY M. SELA, SARA FUCHS AND RUTH ARNON \\ Department of Biophysics, The Weizmann Institute of Science, Rehovoth, Israel
}

\section{(Received 7 March 1962)}

The purpose of the present series of investigations is to determine the minimum definitive chemical features necessary to endow a molecule with immunogenicity, i.e. the capacity to elicit antibodies in an animal. It was also desired to elucidate the antigenic specificity relationships in the materials studied. Here we report results of immunological studies of some synthetic polypeptide antigens.

In discussing immunogenicity and antigenic specificity, one may draw a parallel with enzymes, in which a certain portion of the molecule may be assumed to possess catalytic activity, and another portion, sometimes even overlapping or coinciding with the first, may confer substrate specificity. For

\footnotetext{
* Part 4: Arnon \& Sela (1960a).
}

antigens, one might differentiate between a moiety of the molecule necessary for immunogenicity and another responsible for serological specificity.

Sela \& Arnon $(1960 a, b)$ and Arnon \& Sela $(1960 b)$ showed that gelatin modified by attachment to its amino groups of short peptide chains of tyrosine, tryptophan, phenylalanine and, to a less extent, cysteine, had considerably greater immunogenicity than unmodified gelatin had. The covalent binding of peptides containing alanine, lysine, glutamic acid, serine or proline did not increase the immunogenicity as compared with gelatin. The increase in the immunogenicity through attachment of the aromatic amino acids is not due to their aromatic character. This was demonstrated by showing that the attachment of fully saturated cyclohexylalanine (Sela \& Arnon, 